\title{
Sleep Patterns, Sleep Problems and Associations with Reported Sleep Quality in Chinese School-Aged Children
}

\author{
Zeyu Zhang ${ }^{1}$, Ting Chen ${ }^{1}$, Xingming $\mathrm{Jin}^{2}$, Chonghuai Yan $^{3}$, Xiaoming Shen ${ }^{3}$, Shenghui $\mathrm{Li}^{1{ }^{1, *}}$ \\ ${ }^{1}$ School of Public Health, Shangh ai Jiaotong University, Shanghai, People's Republic of China \\ ${ }^{2}$ Children's Medical Center, School of Medicine, Shan ghai Jiaotong University, Shanghai, People's Republic of China \\ ${ }^{3}$ MOE-Shanghai Key Laboratory of Children's Environmental Health, Xinhua Hospital, Shanghai Jiao Tong University School of \\ Medicine, Shanghai, People's Republic of China \\ *Corresponding author: Shenxm9907@126.com
}

Received April 02, 2013; Revised May 05, 2013; Accepted May 06, 2013

\begin{abstract}
Sleep plays a key role not only in children's physical growth, behavior, and emotional development, but also in cognitive functioning. The present study was designed to survey the sleep characteristics and to examine the associations between sleep characteristics and child-reported sleep quality in urban school-aged children of China. A random sample of 19,299 children aged 5.08 to 11.99 years old, $49.7 \%$ boys and $50.3 \%$ girls with a mean age of 9.00 years old, participated in a cross-sectional survey which was conducted in 8 cities of China. A parentadministered questionnaire and the Chinese version of the Children's Sleep Habits Questionnaire were co mpleted to quantify family and personal information and to characterize sleep behaviors. The mean sleep duration was $9.17 \mathrm{~h}$ $(\mathrm{SD}=0.80)$ on weekdays and $9.80 \mathrm{~h}(\mathrm{SD}=1.06)$ at weekends. Sleep problems were commonly existed with a relatively high prevalence ranging from $14.5 \%$ for sleep-disordered breathing to $75.3 \%$ for daytime sleepiness. There were significant gender and age differences existed in sleep problems. Various kinds of sleep problems and unhealthy sleep patterns were associated with poor sleep quality in Chinese school-aged children. The mean sleep duration was less than the recommended 10 hours per day for school-aged children. Sleep problems were commonly existed, which was beyond our expectation. Sleep problems and unhealthy sleep patterns were harmful to children's sleep quality. A longitudinal study is needed to investigate the trends of sleep behaviors and the relative factors including personal lifestyle, family and social environment so as to intervene and improve children's sleep quality.
\end{abstract}

Keywords: children, sleep patterns, sleep problems, sleep quality

\section{Introduction}

A number of studies have suggested that sleep plays a key role not only in child ren's physical growth, behavior, and emotional development, but also in cognitive functioning, learning and attention [1,2,3,4,5]. Insufficient sleep duration and poor sleep quality can result in significant daytime consequences including excessive daytime sleepiness [5,6], inattention, poor academic performance $[7,8,9]$, increased aggression as well as behavioral problems such as hyperactivity $[2,10,11,12,13]$, decreased reaction time and an increased vulnerability to accidents or injuries $[2,5,14]$. Sleep problems in children are prevalent. In a number of surveys and studies, the prevalence of sleep problems in school-aged children was $30-62 \%[6,15,16]$. The diversity of the prevalence in these studies may be due to the different criteria for defining sleep problems and different sample characteristics. In light of the elevated prevalence and negative consequences of sleep problems, promotion of healthy sleep habits and changes in school schedules have been advocated to improve children's sleep quality $[5,17,18]$. The most marked reductions in sleep duration and the highest prevalence of sleepiness are thought to occur in adolescents, a group in whose sleep patterns have been settled and effective behavioral interventions are difficult to implement $[5,19,20]$. Research has demonstrated that infancy and childhood are periods when sleep patterns are initiated [21]. So sleep patterns and sleep problems of children should be emphasized in order to develop healthy sleep patterns and formulate antecedent intervention schemes for improving the sleep quality of children.

Sleep practices and sleep behaviors in children are associated not only with biologic and psychologic factors but also with cultural, social, and family factors $[4,16,22,23]$. As an Asian country, China has intrinsic sociocultural values and traditional convention which differs greatly from Western countries. As a developing country, China varies from developed countries, even in Asia, such as Korea and Japan, in socioeconomic status. Moreover, China has a unique one-child-family-planning policy. These characteristics may make sleep practices and sleep behaviors of Chinese children different from their peers of other countries. There was evidence that Chinese children have less sleep time and more sleep problems than American children [24]. In addition, although there were a few reports on Chinese children's sleep behaviors $[24,25,26]$, a study based on a large sample of school-age children from diverse ethnic and socioeconomic background has not been reported. Moreover, as far as we 
know, no studies have specifically investigated the association among sleep patterns, sleep problems and subject sleep quality up to now.

The specific purposes of this study were: 1) to describe the sleep patterns and sleep problems in Chinese children. 2) to identify differences in sleep patterns and sleep problems in relation to age and gender. 3) to assess the impacts of sleep patterns and sleep problems on sleep quality in Chinese school-aged children.

\section{Methods}

\subsection{Subjects}

Detailed information on subject enrollment was described previously[27,28]. Briefly, a large national cross-sectional survey was undertaken in eight Chinese cities. These cities were Urumqi, Chengdu, Xi'an, Hohhot, Wuhan, Canton, Shanghai, and Harbin. Adopting a twostage random cluster-sampling design, 39 districts and 55 schools, 30 districts and 42 schools being located in urban areas and 9 districts and 13 schools being located in suburban/rural areas, were selected. Of 23,791 children recruited from six grades of the chosen schools, 22,018 $(92.5 \%)$ returned completed questionnaires.

All students were chosen from nine-year compulsory education elementary schools. Therefore, our sampled children were physically and mentally healthy. We have revised the description of "Subjects" according to the suggestion.

To eliminate the possible pubertal influences on sleep, 1158 children over 11.99 years old were excluded. To control the effects of some diseases and drugs on sleep behavior, 1561 children were excluded due to a parentreported history of the diagnosis with a psychiatric condition, such as ADHD or depression, and/or receiving medication (e.g. psychostimulants, anticonvuls ants, and antihistamines). The final sample consisted of 19,299 children.

The features of this sample indicated that it was geographically and ethnically representative and diverse.

\subsection{Procedure}

This study was conducted in November and December, 2005. The purposes of this research project were explained to school principals and teachers of the target schools. After the permissions were obtained from these schools, students who were eligible to participate in this study were invited to take questionnaire to their parents, with a letter explaining the objectives of the project and instructions on completing the questionnaire. Parents were told that participation in the survey was voluntary and the survey was anonymous. The ethical application of this study was approved by the Ministry of Education of the People's Republic of China.

\subsection{Measure}

\subsubsection{Sleep Patterns and Sleep Problems}

The Children's Sleep Habits Questionnaire (CSHQ) was used to assess children's sleep habits and sleep problems. The CSHQ, developed by Owens et al, consists of 33 sleep-disturbance items and 3 items asking information about bedtime, morning waking time, and daily total sleep duration [29]. The CSHQ is a parentreported pencil-and-paper instrument designed and developed to assess sleep behaviors of pre-school and school-aged children [29]. Parents are asked to indicate how often the child's sleep behaviors have occurred over a typical recent week. Answers are on a 3-point scale: "usually" if the sleep behavior occurred 5-7 nights per week, "sometimes" for 2-4 nights per week, and "rarely" for 0-1 night per week. According to the structure of the CSHQ, the 33 sleep-disturbance items are conceptually grouped into 8 subscales: bedtime resistance, sleep-onset delay, problem of sleep duration, sleep anxiety, night awakening, parasomnias, sleep-disordered breathing, and daytime sleepiness[29]. The CSHQ has satisfactory psychometric properties in US children [29].

An individual sleep problem was defined as a sleep problem occurring at least two nights per week. Based on the scoring system, an indication of a sleep problem was calculated (i.e., prevalence of each subscale disturbance). In the present study, a specific sleep proble $m$ is defined as having at least one individual sleep problem within a respective disturbance-subscale with the exception of the following subscales, which required at least two sleep problems: bedtime resistance and daytime sleepiness. These cut-offs were based upon clinical relevance and literature findings [16,24,28].

A Chinese version of the CSHQ was developed by translation and back translation. Psychometric properties of the Chinese version of the CSHQ were examined. Psychometric properties of the Chinese CSHQ were comparable to those in US children for most of the subscales $[29,30]$.

\subsubsection{Child-Re por ted Sleep Quality}

Sleep quality was investigated by using the following question: how often do you sleep well? Response choices were based on a 3-point Likert scale: "usually" if it occurred 5-7 nights per week; "sometimes" for 2-4 nights per week; and "rarely" for 0-1 night per week. In order to simplify the presentation of the results, sleep quality was then divided into two categories: "good sleep quality" (sleep well 5-7 nights per week) and "poor sleep quality" (sleep well less than 5 nights per week).

\subsubsection{Family Demographics and Child Developmental Characteristics}

This section consisted of children's gender, age, ethnicity, school grade, parent education levels, occupation, household income[RMB(yuan)/person/month], family structure (single-parent family, nuclear family, and large family), and sleep arrange ments. Sleep arrangements were divided into four practices: routine bed-sharing (sharing a bed with parents/caregivers 5-7 nights per week), routine room-sharing (sharing a room with parents/caregivers, but in a different bed 5-7 nights per week), routine sleeping alone (sleeping alone in his/her own bedroom 5-7 nights per week), and other or not having a regular sleep arrangement (all remaining participants). The heights and weights of the children were measured and reported in the questionnaire. Based on the parameters of height and weight, the body mass index 
(BMI) of children was calculated as weight $(\mathrm{kg}) /$ height (m)2 [31].

\subsection{Statistical Analysis}

Statistical descriptions are comprised of the mean, standard deviation, frequencies, and percentages. Paired $t$ tests were used to compare sleep/wake patterns and sleep duration between weekdays and weekends. Gender and age differences in sleep/wake patterns and sleep duration were analy zed by independent-samples t test and one-way ANOVA (analysis of variance), respectively. Two*two and $\mathrm{K}^{*} 2$ Chi-square tests were used to compare gender and age differences in the prevalence of sleep problems and prevalence of inadequate sleep duration, respectively.

Logistic regression analyses were performed to evaluate the impact of sleep/wake patterns, sleep duration, sleep arrangement, and sleep problems on reported sleep quality, with the dependent variable designated as " 1 " for child ren with "poor sleep" and "0" for children with "good sleep". The regression model adopted a forward likelihood-ratio stepwise elimination procedure. Statistical tests of the regression estimates or odds ratios (OR) were based on Wald statistics.

All analyses were performed using the Statistical Program for Social Sciences (SPSS) for Windows, version 12.5. In presentation of the results, the statistical significance was set at $\mathrm{P}<0.05$ (two tailed).

\section{Results}

The mean age of the sample was 9.00 years $(\mathrm{SD}=1.61$; range: 5.08-11.99 years), $49.7 \%$ were boys (mean age = $8.97, \mathrm{SD}=1.58$ ) and $50.3 \%$ were girls (mean age $=9.03$, $\mathrm{SD}=1.63)$. Of the 19,299 children, the vast majority
$(18,242 ; 95.1 \%)$ came from the Han ethnic group and the remaining children $(948 ; 4.9 \%)$ were from the ethnic minority, such as Muslim ethnic group, Mongolia ethnic group, Uighur ethnic group, et al.

\subsection{Sleep/Wake Patterns and Sleep Duration: Variation by Gender and Age}

Table 1 and Table 2 summarized descriptive statistic of sleep/wake habits and sleep duration during weekdays and weekends in Chinese school-aged children.

There were significant differences in bedtime, wakeup time and sleep duration between weekdays and weekends. The mean sleep duration was $9.80 \mathrm{~h}(\mathrm{SD}=1.06)$ at weekends, which was approximately 30 minutes longer than that on weekdays $(9.17 \mathrm{~h}, \mathrm{SD}=0.80)$, indicating the possibility of sleep compensation at weekends. There were statistically significant gender differences in bedtime and wakeup time during weekdays and weekends and sleep duration at weekends (Table 1).

There was a tendency that the older the child was, the later the bedtime $(\mathrm{F}=155.75, \mathrm{P}<0.001)$ was; the earlier the wakeup time $(\mathrm{F}=10.42, \mathrm{P}<0.001)$ was and the shorter the sleep duration $(\mathrm{F}=139.28, \mathrm{P}<0.01)$ was on weekdays. At weekends, such a trend was apparent only for younger children (i.e. 5 to 8 years old) (Table 2).

As shown in Table 3, the percentages of children who slept less than 10 hours per day on weekdays and at weekends were $71.4 \%$ and $41.8 \%$, respectively. There was a significant tendency of increasing prevalence of inadequate sleep duration with increased age. The prevalence reached to $80.0 \%$ during weekdays at the age of 10 and 11. Gender difference existed in prevalence of inadequate sleep at weekends and boys were with higher prevalent.

Table 1. Sleep-wake patterns and sleep duration during weekdays and on weekends by gender.( mean \pm SD)

\begin{tabular}{|c|c|c|c|c|c|}
\hline \multirow{2}{*}{ Variable } & & \multirow[t]{2}{*}{ Total } & \multicolumn{2}{|c|}{ Gender } & \multirow{2}{*}{$\mathrm{t} \S$} \\
\hline & & & Boys & Girls & \\
\hline \multirow[t]{3}{*}{ Bedtime } & Weekday & $21.55 \pm 0.75$ & $21.13 \pm 0.76$ & $21.17 \pm 0.74$ & $-3.21 * *$ \\
\hline & Weekend & $21.88 \pm 0.83$ & $21.86 \pm 0.83$ & $21.90 \pm 0.83$ & $-2.69 * *$ \\
\hline & $t £$ & $-164.73^{* *}$ & $-112.58 * *$ & $-119.82 * *$ & \\
\hline \multirow[t]{3}{*}{ Wake time } & Weekday & $6.64 \pm 0.46$ & $6.65 \pm 0.47$ & $6.63 \pm 0.45$ & $2.38^{*}$ \\
\hline & Weekend & $7.92 \pm 0.93$ & $7.86 \pm 0.91$ & $7.99 \pm 0.94$ & $-9.45 * *$ \\
\hline & $\mathrm{tf}$ & $-217.09 * *$ & $-145.57 * *$ & $-161.49 * *$ & \\
\hline \multirow[t]{3}{*}{ Sleep duration } & Weekday & $9.17 \pm 0.80$ & $9.17 \pm 0.80$ & $9.17 \pm 0.80$ & 0.53 \\
\hline & Weekend & $9.80 \pm 1.06$ & $9.74 \pm 1.06$ & $9.86 \pm 1.06$ & $-8.16 * *$ \\
\hline & $\mathrm{t} £$ & $-88.32 * *$ & $-55.09 * *$ & $-69.29 * *$ & \\
\hline
\end{tabular}

Bedtime, awakening time, and sleep duration were expressed in hours and fractions of hours

$£$ Paired-Samples T Test

$\S$ Independent-Samples T Test

$* \mathrm{P}<0.05 * * \mathrm{P}<0.01$

Table 2.Sleep-wake pattem and sleep duration during weekdays and on weekends by age.( $\operatorname{mean} \pm \mathrm{SD})$

\begin{tabular}{|c|c|c|c|c|c|c|c|c|}
\hline \multirow{2}{*}{\multicolumn{2}{|c|}{ Variable }} & \multicolumn{6}{|c|}{ Ages } & \multirow{2}{*}{$\mathrm{F} £$} \\
\hline & & $5-6$ & 7 & 8 & 9 & 10 & 11 & \\
\hline \multirow[t]{2}{*}{ Bedtime } & Weekday & $20.89 \pm 0.71$ & $21.02 \pm 0.70$ & $21.12 \pm 0.72$ & $21.22 \pm 0.73$ & $21.25 \pm 0.74$ & $21.38 \pm 0.82$ & $155.75 * *$ \\
\hline & Weekend & $21.59 \pm 0.80$ & $21.74 \pm 0.78$ & $21.84 \pm 0.80$ & $21.93 \pm 0.81$ & $21.99 \pm 0.83$ & $22.15 \pm 0.87$ & $157.72 * *$ \\
\hline \multirow[t]{2}{*}{ Wake time } & Weekday & $6.68 \pm 0.45$ & $6.67 \pm 0.45$ & $6.64 \pm 0.44$ & $6.63 \pm 0.47$ & $6.60 \pm 00.46$ & $5.98 \pm 0.48$ & $10.42^{* *}$ \\
\hline & Weekend & $7.73 \pm 0.86$ & $7.83 \pm 0.88$ & $7.87 \pm 0.88$ & $7.96 \pm 0.94$ & $7.99 \pm 0.96$ & $8.18 \pm 1.00$ & $75.85^{* *}$ \\
\hline \multirow[t]{2}{*}{ Sleep duration } & Weekday & $9.44 \pm 0.78$ & $9.33 \pm 0.77$ & $9.18 \pm 0.77$ & $9.07 \pm 0.78$ & $9.04 \pm 0.79$ & $9.01 \pm 0.83$ & $139.28 * *$ \\
\hline & Weekend & $9.94 \pm 1.04$ & $9.85 \pm 1.04$ & $9.76 \pm 1.05$ & $9.76 \pm 1.05$ & $9.73 \pm 1.08$ & $9.83 \pm 1.11$ & $14.32 * *$ \\
\hline
\end{tabular}

Bedtime, awakening time, and sleep duration were expressed in hours and fractions of hours

$* * \mathrm{P}<0.01$

$£$ One-Way ANOVA 
Table 3. Pre valence of inadequate sleep duration du ring week days and on weekends by gender and age

\begin{tabular}{|c|c|c|c|c|c|c|}
\hline & & \multicolumn{4}{|c|}{ Prevalence of inadequate sleep duration $(\%)$} & \multirow[t]{2}{*}{2} \\
\hline & & Weekday & 2 & Weekend & 2 & \\
\hline Total & & 71.4 & & 41.8 & & $1489.19 * * £$ \\
\hline Gender & Boys & 74.3 & $0.03 £$ & 44.5 & $47.66^{* * f}$ & $777.60 * * £$ \\
\hline & Girls & 74.4 & & 39.5 & & $707.91 *_{£}$ \\
\hline Age & $5-6$ & 60.3 & $498.86^{* *} \S$ & 35.9 & $64.97 * \% \S$ & $259.96^{* * f}$ \\
\hline & 7 & 67.4 & & 39.8 & & $321.15 *^{*} *_{£}$ \\
\hline & 8 & 74.8 & & 43.2 & & $282.65 * * £$ \\
\hline & 9 & 79.5 & & 43.8 & & $250.54 * *_{£}$ \\
\hline & 10 & 81.0 & & 45.3 & & $190.04 * *_{£}$ \\
\hline & 11 & 79.8 & & 40.9 & & $143.15^{* * f}$ \\
\hline
\end{tabular}

$£ 2 * 2$ Chi-square Test $\S \mathrm{K}^{* 2}$ Chi-square Test

Prevalence of inadequate sleep duration was assessed by the criterion of "10 hours" which was recommended by the Ministry of Education of the People's Republic of China.

Table 4. Pre valence of sleep problems (\%): variation by gender

\begin{tabular}{|c|c|c|c|c|}
\hline \multirow{2}{*}{ Subscale disorders } & \multirow{2}{*}{ Total } & \multicolumn{2}{|c|}{ Gender } & \multirow{2}{*}{${ }^{2} £$} \\
\hline & & Boys & Girls & \\
\hline Bedtime resist ance & 47.2 & 46.6 & 47.7 & 2.71 \\
\hline Sleep onset delay & 22.2 & 22.5 & 21.9 & 1.05 \\
\hline Sleep duration & 66.6 & 66.5 & 66.5 & 0.03 \\
\hline Sleep anxiety & 54.3 & 52.7 & 55.9 & $19.42 * *$ \\
\hline Night wakings & 25.9 & 26.5 & 25.4 & 2.84 \\
\hline Parasomnia & 55.1 & 56.5 & 53.8 & $13.76^{* *}$ \\
\hline Sleep-disordered breathing & 14.5 & 16.3 & 10.8 & $119.83 * *$ \\
\hline Daytime sleepiness & 75.3 & 74.5 & 76.0 & 5.45 \\
\hline
\end{tabular}

$* \mathrm{P}<0.05 £ 2 * 2$ Chi-square Test

Table 5. Pre valence of sleep problems (\%): variation by age

\begin{tabular}{|c|c|c|c|c|c|c|c|}
\hline \multirow[t]{2}{*}{ Subscale disorders } & \multicolumn{6}{|c|}{ Age } & \multirow{2}{*}{$2 \mathfrak{f}$} \\
\hline & $5-6$ & 7 & 8 & 9 & 10 & 11 & \\
\hline Bedt ime resist ance & 58.5 & 56.2 & 50.6 & 45.4 & 39.6 & 33.1 & $548.60 * *$ \\
\hline Sleep onset delay & 21.0 & 20.9 & 20.3 & 22.8 & 23.3 & 25.4 & $30.89 * *$ \\
\hline Sleep duration & 60.8 & 64.7 & 65.7 & 68.3 & 68.6 & 70.1 & $68.22 * *$ \\
\hline Sleep anxiet y & 65.2 & 61.9 & 58.0 & 52.9 & 47.1 & 41.4 & $463.78 * *$ \\
\hline Night wakings & 24.6 & 25.8 & 25.3 & 25.8 & 26.6 & 27.4 & 6.70 \\
\hline Parasomnia & 60.0 & 57.9 & 55.2 & 53.8 & 52.2 & 52.4 & $54.55 * *$ \\
\hline $\begin{array}{c}\text { Sleep-disordered } \\
\text { breathing }\end{array}$ & 13.5 & 15.2 & 13.6 & 13.5 & 12.8 & 11.9 & $15.93 * *$ \\
\hline Dayt ime sleepiness & 77.3 & 77.2 & 76.4 & 75.5 & 73.7 & 71.2 & $42.81 * *$ \\
\hline
\end{tabular}

\subsection{Sleep Problems, Variation by Gender and Age}

From Table 4 and Table 5, it can be summarized that sleep problems were highly prevalent with prevalences ranging from $14.5 \%$ for sleep-disordered breathing to $75.3 \%$ for daytime sleepiness in Chinese school-aged children. Sleep problems of parasomnias and sleepdisordered breathing were higher prevalent in boys than in girls. However, sleep an xiety was more prevalent in girls than in boys. The other five types of sleep problems showed no significant gender differences. Except nighttime wakening, all sleep problems differed significantly with age. The prevalence of four types of sleep problems (bedtime resistance, sleep anxiety, parasomnias, and daytime sleepiness) decreased with increased age. However, the prevalence of sleep onset delay and problem of sleep duration increased with age. For sleep-disordered breathing, prevalence was significantly related to age, but without a linear association, fluctuating with the highest $(15.2 \%)$ at 7 years old and then gradually decreasing to $11.9 \%$ at 11 years old.

\subsection{Associations Between Sleep Behaviors and Child-Reported Sleep Quality}

Results of univariate and multivariate logistic regression analyses on the sleep quality with sleep/wake patterns, sleep duration, sleep problems and sleep arrangement are shown in Table 6 . After controlling for potential confounding effects, eight factors were significantly associated with an increased likelihood of poor sleep quality: child with various kinds of sleep problems (bedtime resistance: $\mathrm{OR}=1.82, \mathrm{p}<0.01$; sleep onset delay: $\mathrm{OR}=2.22, \mathrm{p}<0.01$; problem of sleep duration: $\mathrm{OR}=2.27, \mathrm{p}<0.01$; s leep an xiety: $\mathrm{OR}=1.51, \mathrm{p}$ $<0.01$; night waking: $\mathrm{OR}=1.97, \mathrm{p}<0.01$; parasomnia: $\mathrm{OR}=2.39, \mathrm{p}<0.01$; sleep-disordered breathing: $\mathrm{OR}=$ $2.43, \mathrm{p}<0.01)$, later bedtime during weekdays $(\mathrm{OR}=1.16$, $\mathrm{p}<0.01)$, later wake time on weekends $(\mathrm{OR}=1.31, \mathrm{p}<$ 0.01 ), and shorter sleep duration during weekdays $(\mathrm{OR}=$ $0.86, \mathrm{p}<0.01)$.

\section{Discussion}

Utilizing a large general sample, this study demonstrated that insufficient sleep duration and sleep 
problems are very common in Chinese school-aged children. Daytime sleepiness appears to be the most prevalent in this age group, with approximately threefourths of children having the problem. Various kinds of sleep problems and unhealthy sleep patterns (such as later bedtime during weekdays, later wakeup time at weekends and shorter sleep duration on weekdays) are harmful to children's sleep quality.

Table 6. The impact of sleep behaviors on children's reported sleep quality by logistic regression models

\begin{tabular}{|c|c|c|c|c|c|c|}
\hline Variable & \multicolumn{3}{|c|}{ Univariate Model } & \multicolumn{3}{|c|}{ Multivariate Model } \\
\hline & $\bar{B}$ & OR & $95 \%$ CI & $\bar{B}$ & OR & $95 \% \mathrm{CI}$ \\
\hline Bedtime resistance & & & & & & \\
\hline Yes & 0.64 & $1.89 * *$ & $1.86^{\sim} 1.93$ & 0.60 & $1.82 * *$ & $1.76 \sim 1.89$ \\
\hline No & & 1.00 & & & 1.00 & \\
\hline Sleep onset delay & & & & & & \\
\hline Yes & 0.91 & $2.48^{* *}$ & \begin{tabular}{l|l}
2.34 & 2.63 \\
\end{tabular} & 0.80 & $2.22 * *$ & $2.03 \quad 2.43$ \\
\hline No & & 1.00 & & & 1.00 & \\
\hline Problem of sleep duration & & & & & & \\
\hline Yes & 0.56 & $1.75^{* *}$ & $1.71 \sim 1.79$ & 0.82 & $2.27 * *$ & $2.19 \sim 3.36$ \\
\hline No & & 1.00 & & & 1.00 & \\
\hline Sleep anxiety & & & & & & \\
\hline Yes & 0.68 & $1.97 * *$ & $1.92 \sim 2.01$ & 0.41 & $1.51 * *$ & $1.45 \sim 1.57$ \\
\hline No & & 1.00 & & & 1.00 & \\
\hline Night wakings & & & & & & \\
\hline Yes & 0.64 & $1.90^{* *}$ & $\begin{array}{ll}1.82 & 1.99\end{array}$ & 0.68 & $1.97 * *$ & $1.84 \quad 2.11$ \\
\hline No & & 1.00 & & & 1.00 & \\
\hline Parasomnia & & & & & & \\
\hline Yes & 0.67 & $1.96^{* *}$ & $1.91 \sim 2.02$ & 0.87 & $2.39 * *$ & $2.28 \sim 2.50$ \\
\hline No & & 1.00 & & & 1.00 & \\
\hline Sleep-disordered breathing & & & & & & \\
\hline Yes & 0.99 & $2.69 * *$ & $2.49 \quad 2.91$ & 0.89 & $2.43 * *$ & $2.15 \quad 2.74$ \\
\hline No & & 1.00 & & & 1.00 & \\
\hline Bedtime weekday & 0.31 & $1.37 * *$ & $1.32 \sim 1.43$ & 0.15 & $1.16^{* *}$ & $1.05 \sim 1.28$ \\
\hline Bedtime weekend & 0.29 & $1.34^{* *}$ & $1.29 \quad 1.39$ & 0.08 & 1.08 & $\begin{array}{ll}0.99 & 1.19\end{array}$ \\
\hline Wake time weekday & 0.40 & $1.50 * *$ & $1.40 \approx 1.60$ & 0.01 & 1.01 & $0.88 \sim 1.16$ \\
\hline Wake time weekend & 0.30 & $1.35^{* *}$ & $\begin{array}{ll}1.30 & 1.39\end{array}$ & 0.27 & $1.31 * *$ & $\begin{array}{ll}1.22 & 1.41\end{array}$ \\
\hline Sleep duration weekday & -0.26 & $0.77 * *$ & $0.74 \widetilde{0.80}$ & -0.15 & $0.86^{* * *}$ & $\overline{0.80 \widetilde{0.93}}$ \\
\hline Sleep duration weekend & 0.01 & $1.01^{* *}$ & $\begin{array}{ll}0.98 & 1.04\end{array}$ & 0.06 & 1.07 & $\begin{array}{ll}.01 & 1.23\end{array}$ \\
\hline Regular bed sharing & & & & & & \\
\hline Yes & 1.22 & 3.39 & $3.15 \sim 3.66$ & 0.11 & 1.12 & $0.95^{\sim} 1.32$ \\
\hline No & & 1.00 & & & 1.00 & \\
\hline Regular room sharing & & & & & & \\
\hline Yes & 0.84 & $2.32 * *$ & $\begin{array}{ll}2.18 & 2.47\end{array}$ & 0.02 & 1.02 & $\begin{array}{ll}0.89 & 1.16\end{array}$ \\
\hline No & & 1.00 & & & 1.00 & \\
\hline
\end{tabular}

Multivariate regression model controlled for children's age, gender, BMI, parents educational levels, family income, and family struct ure

OR: odds ratio CI: confidence interval

$* * \mathrm{P}<0.01$

\subsection{Sleep/Wake Patterns and Sleep Duration}

The mean sleep duration was $9.17 \mathrm{~h}(\mathrm{SD}=0.80)$ on weekdays and $9.80 \mathrm{~h}(\mathrm{SD}=1.06)$ at weekends. There were $71.4 \%$ and $41.8 \%$ of school-aged children not getting adequate sleep time on weekdays and at weekends respectively. In agreement with previous findings $[14,16,32]$, our study showed that bedtime was significantly postponed, wakeup time advanced, and total sleep duration significantly declined on weekdays with increasing age. In comparison with sleep duration during weekdays, children slept approximately 30 minutes longer at weekends, which was similar to other findings [16,33]. The present study indicated that girls had approximately seven minutes longer sleep duration than boys at weekends, which was in consistent with the results of studies among Belgium and American school-aged children $[6,16,34]$. However, this small difference is unlikely to be clinically significant, which should be further studied.

Compared with American and Belgium children, Chinese school-aged children approximately slept less half an hour to nearly one hour [16,34]. The differences in sleep duration may be physiologically significant since a research showed that a child who sleeps 1h less than the average child may be at risk of conduct problems $[35,36]$. In addition, there were evidences that inadequate sleep duration can cause a range of neurobehavioral deficits, including lapses of attention, slowed working memory, reduced cognitive throughput, and depressed mood $[37,38,39]$. Because there is no evidence to show that Chinese children require less sleep than western children, it is essential to take measures to increase Chinese children's sleep duration, and it may potentially improve their neurobehavioral functioning and academic performance.

The differences in sleep duration between Chinese and Western children suggest that a variety of sociocultural and environmental factors may influence children's sleep patterns. The first one is the schedule of school. Elementary schools of China start at 7:30-8:00, end at 16:00-17:00. Whereas in America, elementary schools start at 9:00, end at 14:00-15:00. The second one is that Chinese society has a tradition of Confucianis $\mathrm{m}$, in which special emphasis is put on education. It is well known that Chinese students have more homework than their peers in the West and most urban children attend sorts of private educational classes in the evening and/or at weekend, which can undoubtedly occupy children's sleep time. Our 
survey showed nearly $10.0 \%$ of child ren felt overburdened with their schoolwork, $54.3 \%$ and $24.5 \%$ of children routinely have to do homework for 1-2 or above 2 hours, and nearly $70 \%$ of urban school-aged children have sorts of supplemental learning plans such as drawing, music, dancing, etc.

\subsection{Sleep Problems}

Sleep problems were commonly existed with prevalence ranging from $14.5 \%$ for sleep-disordered breathing to $75.3 \%$ for daytime sleepiness. Previous studies showed that daytime sleepiness was the most prevalent sleep problem in non-clinical population of school-aged and adolescent children [16,40]. Our study demonstrated that nearly three-fourths of Chinese schoolaged children existed daytime sleepiness. In a survey of 9,261 Japanese school children with mean age of 12.8 years old, similar findings resulted: $25.2 \%$ of children reported sleepiness almost always and $47.6 \%$ sleepiness often [40,41]. But a study in Belgium school-aged children showed that the prevalence of daytime sleepiness was $36.88 \%$ [16], which was obviously lower than in Chinese children. Despite of the discrepancy of the prevalence, daytime sleepiness in children should be as a "major societal concern" and be paid more attention since it has a profound negative effect on children's daytime performance $[42,43]$.

Studies on effects of gender and age on sleep problems in children were scanty and the results were not consistent. There were evidences that sleep problems showed age or/and gender differences [44], but a recent study in Italian children suggested that no age and gender differences were observed in sleep problems [45]. Our study demonstrated that sleep problems of parasomnia and sleep-disordered breathing were higher prevalent in boys than in girls, while sleep an xiety was higher prevalent in girls than in boys. With increasing age, prevalences of bedtime resistance, sleep anxiety, parasomnia, and daytime sleepiness were gradually lower, while prevalences of sleep onset delay and problem of sleep duration were gradually higher.

The gender and age differences in sleep problems may be the reflection of developmental characteristics of children. Gender difference exists not only in growth pace and physical trait, but also in personality and temperament, which may result in different behavioral tendency and disease sensitivity. For example, compared with boys, girls tend to be timid and restrained, which could increase the odds of sleep anxiety. School-aged childhood is marked by increasing cognitive and emotional development. During this age period, emotional impulse gradually decreases, and emotional modulating function gradually matures $[46,47]$. This may be the cause of reduction of bedtime resistance and sleep anxiety with increasing age. Specific sleep problem of arousal parasomnia decreases with maturation of neural system and reduction of slow wave sleep since it has the characteristic of developmental change [48]. That is why parasomnia gradually decreases with age. Sleep patterns in pre-adolescent children become more challenged because there is often less parental control over bedtimes, coupled with children's increasing academic and social activities in this age stage. And it may result in problem of sleep duration becoming higher prevalent with increasing age.

\subsection{Associations Between Sleep Behavions and Child-Reported Sleep Quality}

To our knowledge, no studies have specifically investigated the association between sleep patterns, sleep problems and sleep quality. Our study indicated that various kinds of sleep problems and unhealthy sleep patterns (including later bedtime during weekdays; later wake time on weekends and shorter sleep duration during weekdays) were associated with poor sleep quality in Chinese school-aged children. A study in medical students found that poor sleep quality was correlated with difficulties in initiating and maintaining sleep and parasomnia, which partly supports our findings [49]. In agreement with our study, several researches on associations between sleep quality and sleep hygiene also demonstrated that unhealthy sleep hygiene, such as later bedtime and shorter sleep duration, was related to poor sleep quality [50,51]. There were evidences that bed sharing children were more likely to have increased sleep problems. Bed sharing may have potential effects on the children's sleep quality $[28,30,52]$. However, our study didn't show bed sharing or room sharing negatively effected children's reported sleep quality in China. So the long-term effect of sleep arrangement on sleep problems and sleep quality should be further prospectively investigated.

\subsection{Limitations}

There are several limitations that should be considered in interpreting the results. The first limitation is the reliance on parental reported data on children's sleep behaviors without objective confirmation, which may have increased the possibility of rater biases and inaccuracy. In addition, subjective sleep quality came from a child, which may be not very accurate. However, it is the only way to get information regarding subjective sleep perception.

Secondly, although we controlled for some potential confounding factors that could affect children's sleep quality, some residual confounding is possible. For example, the factors such as children's health condition, psychologic factors (e.g. emotion, temperament), and environmental factors (e.g. bedroom light, background noise) may be significantly associated with children's sleep quality, so these factors may be potential confounders in assessing the relationship between sleep behaviors and sleep quality. Thirdly, our sample was only representative of general children in urban and suburban areas of China and the results are not generalizable to individuals from pediatric clinics or rural populations. Finally, the present study was designed as a cross sectional survey. Therefore, the results of our study should be further confirmed through prospective study.

\section{Conclusions}

To our knowledge, this is the first research about sleep behaviors and associations with child-reported sleep quality among a large sample of school-age children of 
diverse ethnic and socioeconomic background in China. This study not only exhibited the sleep-wake patterns, sleep duration, sleep problems, and the variations by age and gender but also specifically examined the impact of sleep behaviors on sleep quality. Based on the results of our study, we advocate a good sleep hygiene in order to improve children's sleep quality.

\section{Acknowledgement}

We would like to express our thanks to Dr. Judith A. Owens for her permission and guidance regarding the use of the Children's Sleep Habits Questionnaire. This study was funded by Grants from MOE-Shanghai Key Laboratory of Children's Environmental Health (06DZ22024), the Key Discipline in Public Health of Shanghai Municipal Education Commission, National Natural Science Foundation of China (81072314, 30700670), Innovation Program of Shanghai Municipal Education Commission (09YZ92, 13YZ034), 2009 New Bairenjihua in Shanghai Jiaotong University School of Medicine, 2012 Shanghai public health academic leader project (GWDTR201222), and National Undergraduates Innovating Experimentation Project (2012033).

\section{Competing Interests}

All authors have indicated no financial conflicts of interests.

\section{References}

[1] Amschler, D.H., McKenzie, J.F., "Elementary Students' Sleep Habits and Teacher Observations of Sleep-Related Problems", $J$ Sch Health, 75(2). 50-56. Feb.2005.

[2] DeVincent, C.J., Gadow, K.D., Delosh, D., Geller, L., "Sleep disturbance and its relation to DSM-IV psychiatric symptoms in preschool-age children with pervasive developmental disorder and community controls," J Child Neurol, 22(2). 161-9. Feb.2007.

[3] Curcio, G., Ferrara, M., De Gennaro, L., "Sleep loss, learning capacity and academic performance," Sleep Med Rev, 10(5). 323337. Oct. 2006

[4] Stores, G., "Children's sleep disorders: modern approaches, developmental effects, and children at special risk," Dev Med Child Neurol, 41(8). 568-73. Aug.1999.

[5] Beebe, D.W., "Cognitive, Behavioral, and Functional Consequences of Inadequate Sleep in Children and Adolescents," Pediatr Clin North Am. 58(3). 649-665. Jun.2011.

[6] Hoedlmoser, K., Kloesch, G., Wiater, A., Schabus, M., "Selfreported sleep patterns, sleep problems, and behavioral problems among school children aged 8-11 years,"Somnologie (Berl), 14(1). 23-31. Mar.2010.

[7] Smaldone, A., Honig, J.C., Byrne, M.W., "Sleepless in America: inadequate sleep and relationships to health and well-being of our nation's children," Pediatrics. 119. S29-37. Feb.2007.

[8] Blunden, S.L., Chervin, R.D., "Sleep problems are associated with poor outcomes in remedial teaching programmes: A preliminary study," J Paediatr Child Health. 44(5). 237-42. May.2008.

[9] Dewald, J.F., Meijer, A.M., Oort, F.J., Kerkhof, G.A., Bögels, S.M., "The influence of sleep quality, sleep duration and sleepiness on school performance in children and adolescents: A meta-analytic review," Sleep Med Rev. 14(3). 179-189. Jun.2010.

[10] Carvalho Bos, S., Gomes, A., Clemente, V., Marques, M., Pereira, A.T., Maia, B., Soares, M.J., Cabral, A.S., Macedo, A., Gozal, D., Azevedo, M.H., "Sleep and behavioral/emotional problems in children: A population-based study," Sleep Med. 10(1). 66-74. Jan.2009.
[11] Paavonen, E.J., Räikkönen, K., Lahti, J., Komsi, N., Heinonen, K., Pesonen, A.K., Järvenpää, A.L., Strandberg, T., Kajantie, E., Porkka-Heiskanen, T., "Short sleep duration and behavioral symptoms of attention-deficit/hyperactivity disorder in healthy 7 to 8-year-old children," Pediatrics. 123(5). e857-864. May.2009.

[12] Paavonen, E.J., Porkka-Heiskanen, T., Lahikainen, A.R, "Sleep quality, duration and behavioral symptoms among 5-6-year-old children," Eur Child Adolesc Psychiatry. 18(12). 747-754. Dec.2009.

[13] Willoughby, M.T., Angold, A., Egger, H.L., "Parent-reported attention-deficit/ hyper- activity disorder symptomatology and sleep problems in a preschool-age pediatric clinic sample," $J \mathrm{Am}$ Acad Child Adolesc Psychiatry. 47(9). 1086-94. Sep.2008.

[14] Owens, J.A., Fernando, S., Mc Guinn, M., "Sleep disturbance and injury risk in young children," Behav Sleep Med. 3(1). 18-31. 2005

[15] Fricke-Oerkermann, L., Plück, J., Schredl, M., Heinz, K., Mitschke, A., Wiater, A., Lehmkuhl, G., "Prevalence and course of sleep problems in childhood," Sleep, 30(10). 1371-1377. Oct.2007

[16] Spruyt, K, O'Brien, L.M., Cluydts, R.., Verleye, G.B., Ferri, R., "Odds, prevalence and predict ors of sleep problems in school-age normal children," J Sleep Res, 14(2). 163-76. Jun.2005.

[17] Dahl, R.E., Lewin, D.S., "Pathways to adolescent health: sleep regulation and behavior," J Adolesc Health, 31(6). 175-84. Dec.2002.

[18] Meltzer, L.J., Johnson, C., Crosette, J., Ramos, M., Mindell, J.A., "Prevalence of Diagnosed Sleep Disorders in Pediatric Primary Care Practices. Pediatrics,” 125(6). e1410-e1418. Jun.2010.

[19] Carskadon, M.A., Wolfson, A.R., Acebo, C., Tzischinsky, O., Seifer, R., "Adolescent sleep patterns, circadian timing, and sleepiness at a transition to early school days," Sleep, 21(8). 87181. Dec.1998.

[20] Yang, C.K., Kim, J.K., Patel, S.R., Lee, J.H., "Age-related changes in sleep/wake patterns among Korean teenagers," Pediatrics, 115(1). 250-6. Jun.2005.

[21] Cunnane, SC., "Children origins of lifestyle-related risk factors for coronary heart disease in adulthood," Nutr Health, 23(2). 98105.1993

[22] Adam, E.K., Snell, E.K., Pendry, P., "Sleep timing and quantity in ecological and family context: a nationally representative timediary study," J Fam Psychol, 21(1). 4-19. Mar.2007.

[23] Olds, T., Blunden, S, Petkov, J.,.Forchino, F., "The relationships between sex, age, geography and time in bed in adolescents: A meta-analysis of data from 23 countries," Sleep Med Rev, 14(6). 371-8. Dec.2010

[24] Liu, X., Liu, L., Owens, J.A., Kaplan, D.L, "Sleep patterns and sleep problems among schoolchildren in the United States and China," Pediatrics, 115(1). 241-9. Jan.2005.

[25] Liu, X., Sun, Z., Uchiyama, M., Shibui, K., Kim,. K, Okawa, M., "Prevalence and Correlates of Sleep Problems in Chinese Schoolchildren," Sleep, 23(8). 1053-62. Dec.2000.

[26] Liu, X.C, Liu, L.Q., Wang, R.Z., "Bed sharing, sleep habits, and sleep problems among Chinese school-aged children," Sleep, 26(7). 89-94. Nov.2003.

[27] Li, S., Zhu, S, Jin, X., et al. Risk factors associated with short sleep duration among Chinese school-aged children. Sleep Med 2010; 11:907-16.

[28] Li, S., Jin, X., Wu, S., Jiang, F., Yan, C., Shen, X., "The impact of media use on sleep patterns and sleep disorders among schoolaged children in China," Sleep, 30(3). 361-7. Mar.2007.

[29] Owens, J.A., Spirito, A., McGuinn, M., "The Children's Sleep Habits Questionnaire (CSHQ): psychometric properties of a survey instrument for school-aged children," Sleep, 23(8).1043-51. Dec. 2000.

[30] Li, S.H., Jin, X.M., Shen, X.M., Wu, S.H., Jiang, F., Yan, C.H., Yu, X.D., Qiu, Y.L., "Development and psychometric properties of the Chinese version of Children's Sleep Habits Questionnaire," Zhonghua Er Ke Za Zhi, 45(3). 176-80. Mar. 2007.

[31] Cole, T.J., Bellizzi, M.C., Flegal, K.M., Dietz, W.H.. Establishing a standard definition for child overweight and obesity worldwide: international survey. BMJ. 2000 May 6; 320(7244):1240-3.

[32] Matricciani, L., Olds, T., Petkov, J., "In search of lost sleep: secular trends in the sleep time of school-aged children and adolescents," Sleep Med Rev, 16(3). 203-11. Jun.2012.

[33] Leger, D., Beck, F., Richard, J.B., Godeau, E., "Total sleep time severely drops during adolescence," PLoS One .7(10). e45204. Oct.2012. 
[34] Spilsbury, J.C., Storfer-Isser, A., Drotar, D., Rosen, C.L., Kirchner, L.H., Benham, H., Redline, S., "Sleep behavior in an urban US sample of school-aged children," Arch Pediatr Adolesc Med, 158(10). 988-94. Oct.2004.

[35] Holley, S., Hill, C.M., Stevenson, J., "An hour less sleep is a risk factor for childhood conduct problems," Child Care Health Dev, 37(4). 563-70. Jul.2011.

[36] Gruber, R., Cassoff, J., Frenette, S., Wiebe, S., Carrier, J., "Impact of Sleep Extension and Restriction on Children's Emotional Lability and Impulsivity," Pediatrics. 130(5). el 155-61. Nov.2012.

[37] Banks, S., Dinges, D.F., "Behavioral and physiological consequences of sleep restriction," J Clin Sleep Med. 3(5). 519-28. Aug.2007.

[38] Jiang, F., VanDyke, R,D., Zhang, J., Li, F., Gozal, D., Shen, X., "Effect of chronic sleep restriction on sleepiness and working memory in adolescents and young adults," $J$ Clin Exp Neuropsychol, 33(8). 892-900. Aug.2011.

[39] Goel, N., Rao, H., Durmer, J,S., Dinges, D.F., "Neurocognitive consequences of sleep deprivation," Semin Neurrl. 29(4). 320-39. Sep.2009.

[40] Wang, G., Xu, G., Liu, Z., Lu, N., Ma, R, Zhang, E., "Sleep patterns and sleep disturbances among Chinese school-aged children: Prevalence and associated factors," Sleep Med. 14(1). 45-52. Jan.2013.

[41] Gaina, A., Sekine, M., Hamanishi, S., Chen, X., Wang, H., Yamagami, T., Kagamimori, S., "Daytime sleepiness and associated factors in Japanese school children," J Pediatr, 151(5). 518-22. Nov. 2007.

[42] Ng, E.P., Ng, D.K., Chan, C.H., "Sleep duration, wake/sleep symptoms, and academic performance in Hong Kong Secondary School Children," Sleep Breath. 13(4). 357-67. Nov.2009.

[43] Bahammam, A.S., Alaseem, A.M., Alzakri, A.A, Almeneessier, A.S., Sharif, M.M., "The relationship between sleep and wake habits and academic performance in medical students: a crosssectional study," BMC Med Educ, 12. 61. Aug.2012.

[44] Borchers, C, Randler, C., "Sleep-Wake Cycle of Adolescents in Côte d'Ivoire: Influence of Age, Gender, Religion and Occupation," Chronobiol Int. 29(10). 1366-75. Dec.2012.

[45] Russo, P.M., Bruni, O., Lucidi, F., Ferri, R., Violani, C., "Sleep habits and circadian preference in Italian children and adolescents," J Sleep Res, 16(2). 163-9. Jun. 2007.

[46] Bee, H., "The development child," 5th ed. New York: Harper \& Row Publishers, 1989.

[47] Dwyer, S.B., Nicholson, J.M., Battistutta, D, "Parent and teacher identification of children at risk of developing internalizing or externalizing mental health problems: a comparison of screening methods," Prev Sci, 7(4). 343-57. Dec.2006.

[48] Pressman, M.R., "Disorders of arousal from sleep and violent behavior: the role of physical cont act and proximity," Sleep, 30(8). 1039-47. Aug.2007.

[49] Veldi, M., Aluoja, A., Vasar, V., "Sleep quality and more common sleep-related problems in medical students," Sleep Med. 6(3). 26975. May.2005.

[50] Sun, W.Q., Chen, W.J., Jiang, Y.R., Li, F., Li, S.H., Yan, C.H., Jin, X.M., Shen, X.M., Jiang, F., "The association of sleep hygiene and sleep quality among school-age children," Zhonghua Yu Fang Yi Xue Za Zhi. 46(8). 713-7. Aug.2012.

[51] Suen, L.K., Tam, W.W., Hon, K.L., "Association of sleep hygiene-related factors and sleep quality among university students in Hong Kong," Hong Kong Med J, 16(3). 180-5. Jun.2010,

[52] Li, S., Jin, X., Yan, C., Wu, S., Jiang, F., Shen, X., "Bed- and room-sharing in Chinese school-aged children: prevalence and association with sleep behaviors," Sleep Med, 9(5).555-63. Jul.2008 